\title{
Interfaces of Fiction: Buddha.mov (2017) and Smartphone Aesthetics
}

\author{
Max Bergmann
}

DOI: 10.15664/fcj.v18i1.2258

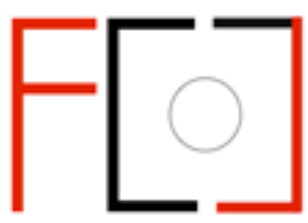

Frames Cinema Journal ISSN 2053-8812 


\title{
Interfaces of Fiction: Buddha.mov (2017) and Smartphone Aesthetics
}

\author{
Max Bergmann
}

Buddha.mov (Kabir Mehta, 2017) is a hybrid project, a mix of documentary and narrative film that never quite reveals its relationship to reality. It follows Buddhadev Mangaldas, a distant cousin of director Kabir Mehta and a cricket player in Goa. The film shows him navigating his personal relationships, including graphic scenes of his sex life, and contemplating the time after his early retirement from professional sports. Increasingly, it becomes unclear if the filmed scenes are indeed documentary, or whether they were planned or even manufactured. In depicting Mangaldas's life, Bhudda.mov uses smartphone aesthetics that consist of overlays or split screens of the director's (or his persona's) phone and its interfaces, including chat messaging, dating apps, and supposedly original videos filmed by the characters.

The film uses these strategies to blur the line between fiction and nonfiction and produces a sense of authenticity through these characteristic (and familiar) markers of contemporary phone displays. In addition to their narrative significance in relaying life events of the protagonist, the interfaces interrogate the nature of the images on both phone and cinematic screens, probing their link to reality and indexicality. This essay argues that Buddha.mov is thereby able to connect its primary theme - social life and relationships in the age of the smartphone - to larger questions about documentary cinema, mediated communication, and self-fashioning via apps and social media. Just as users may create idealised digital selves, the film seemingly alternates between fact and fiction and modes of filmmaking. 


\section{Smartphone Aesthetics}

On its surface, Buddha.mov presents many of the conventional markers of documentary film: location shooting, ambient sound, long static shots that simply observe events, and interview sequences spoken directly into the lens. ${ }^{1}$ Moreover, the beginning of the film places it in line with sport documentaries, which often include training sequences and behind-thescenes footage. ${ }^{2}$ In the first minutes, there are static shots of the protagonist training in a gym and an outside pool. Composed with several mirrors visible or shot in front of a spectacular sky at dusk, these shots are visually interesting but convey the routines of a professional sports player soberly. Very quickly, this conventional set of scenes is ruptured, as the same technique - a distant, immoveable camera - is used to view into a bedroom through a door frame, showing an explicit sex scene of Mangaldas and an unnamed woman. After the cut, the camera is placed nearer to the bed, Mangaldas lying down and staring at his smartphone (fig. 1 and 2). It is no coincidence that these two shots, the first instances of a clear break with the usual sport documentary, both include internal frames that approach the vertical format of a smartphone. Both the sex and the following phone session are framed through doorways or curtains (perhaps of the balcony). Along with the protagonist's intent stare on the device in the latter scene, they clearly mark one of the dominant topics the film will explore: the proliferation of screens, intimacy in the age of self-documentation, and the effect of phones on social life and relationships. 

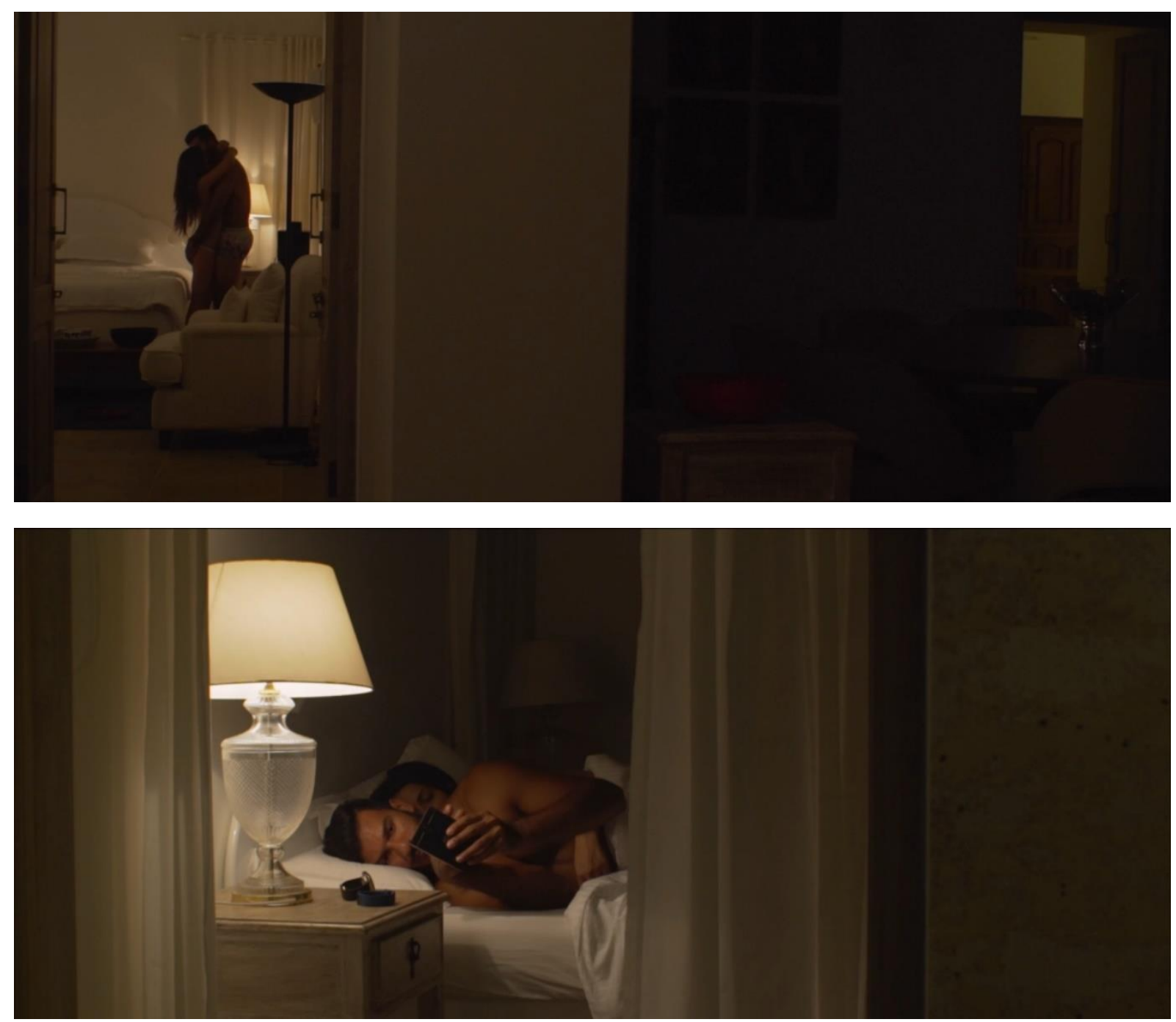

Figure 1 and 2: Two shots using internal vertical framing.

Soon after this initial introduction to one of its core concerns, the film begins to mix the standard procedures of documentaries with aesthetics that speak directly to the current technoculture as well as to Mangaldas's entanglement in digital media. Juxtaposed with observational shots of him playing a professional cricket game, Buddha.mov suddenly integrates images of a phone screen (supposedly of the director), showing a WhatsApp chat with Mangaldas, where the latter shares screenshots of other chats with women, photos, voice messages and mobile videos he has allegedly filmed. For a while, the background image switches to the large "jumbotron" screen of the stadium (fig. 3), aptly visualising what Vivian Sobchack calls today's "screen-sphere": multiplying screens in all sizes and situations 
alongside increased networking capacities and ubiquitous computing. ${ }^{3}$ Soon after, the cursor on the phone plays a WhatsApp voice message of Mangaldas in which he talks about keeping in touch with the ninety plus women he has slept with, via a rotating system enabling him to message five of them each day. Meanwhile, the phone screen switches to his Instagram page, presenting the images he has posted, unfolding his luxurious life in the scroll.
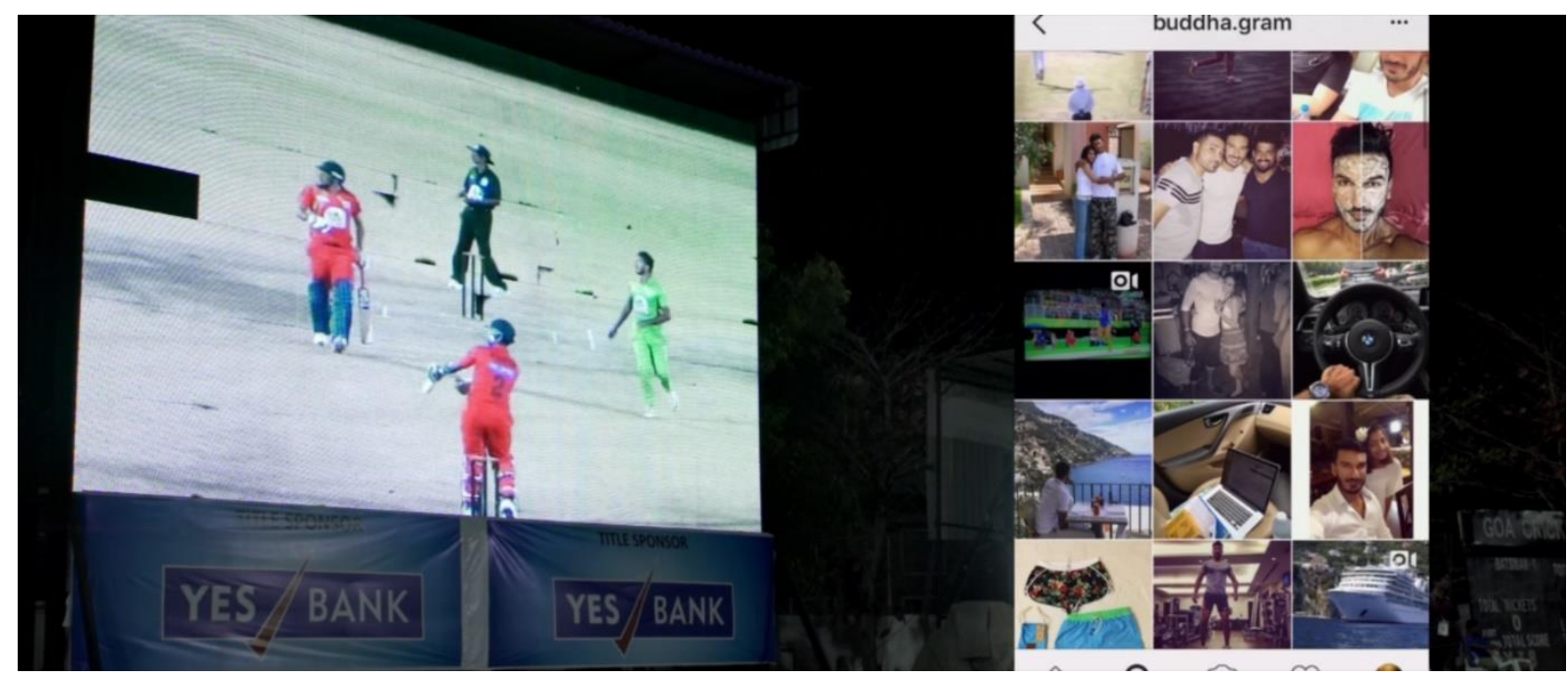

Figure 3: Jumbotron and Instagram feed.

This is a major part of the aesthetics of Buddha.mov, as it mixes regular frames with the phone screen; with videos playing in a VLC player creating split screens; or with Facebook posts or full screen Google searches, as in a desktop film. ${ }^{4}$ Still, the iPhone comes to occupy the screen most frequently, often showing the aforementioned WhatsApp chat, but sometimes switching to the homescreen and to apps like Instagram, YouTube, or Tinder - not coincidentally all image-based platforms. In his studies on digital interfaces as spaces that order, but also cloud, steer, and regulate the user experience, Jan Distelmeyer has called the arrangement of the digital screen "interface mise-en-scène." The term mise-en-scène is, of course, borrowed from film studies, and Distelmeyer uses it to denote the power the interface wields over users, its artificiality and not least its "aesthetics of regulation [Ästhetik der Verfügung]." ${ }^{6}$ While I will return to these normative connotations of the term in relation to 
Buddha.mov later, it is more important to acknowledge the familiarity of the phone's display at this point. Viewers may recognise the iPhone's interface mise-en-scène, the structure of its homescreen, the apps and the act of scrolling, contributing to a sense of authenticity that suggests unfiltered access to Mangaldas's life. Their strategic use alongside more conventional documentary techniques establishes the interface as an authenticating marker, as apparent proof of the film's steadfast connection to reality.

\section{Fact and Fiction, Documentary or Narrative}

Over its runtime, Buddha.mov develops an increasingly complex relationship between its images and the documentary realism they supposedly represent. After around twenty minutes, another voice message from Mangaldas is played, in which he suggests fictionalising or re-shooting certain scenes. He goes on to tell a long, rambling and sexually explicit story of a vengeful ex-girlfriend who allegedly used oral sex to try and poison him, again juxtaposed with static, observational shots. This time, however, these do not show Mangaldas, but the caretaker of his house, cleaning the living room, watering plants in the garden. The stark contrast between the outlandish story, Mangaldas's suggestion to re-shoot the incident ("Imagine the scenario on film," as he remarks at one point), and the conventional documentary mode is jarring, especially since the focus has shifted to the lower-class employee. This unease is only heightened shortly afterwards: Mangaldas's story has ended, and we see the caretaker eat his lunch on an outside staircase, when the director's voice can be heard from off-screen: "Fuck, this is good stuff, man! Festivals love this class shit, you know?!" This metacommentary, as well as several instances where actual .mov-files can be seen played back on a Mac computer, turn the self-reflexive mode of certain documentary styles, most prominently cinema verité, on its head. While these documentaries frequently thematise the process of their own filming, Buddha.mov parodies this reflexivity with the commentary, and most pointedly in the post-credits scene: the film image is simulated to exit the full screen mode of the VLC player 
to reveal a computer desktop. The cursor closes the software and a folder, before finally dragging the file of the completed film - buddha.gram.mov, an earlier title of the project - from the desktop into the Mac's trash, emptying it and shutting the device off. ${ }^{7}$

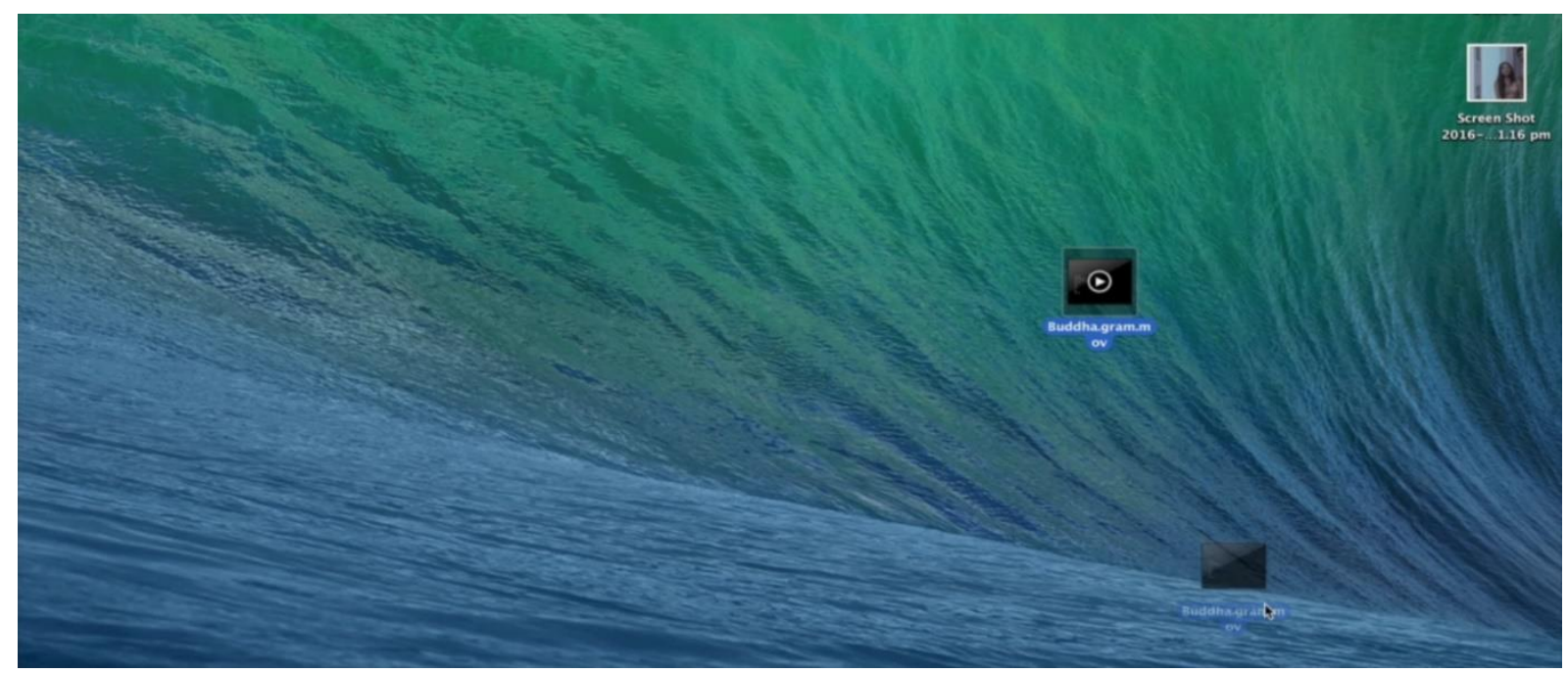

Figure 4: Dragging the file into the trash

The scene juxtaposing the story and the caretaker is indicative of the mode employed from then on, treading the line between fact and fiction, but never quite revealing the extent to which scenes are reshot, staged, or outright manufactured. Director Kabir Mehta calls this "docu-fiction" and it reveals his past as a former assistant of Ashim Ahluwalia, who has explored this kind of filmmaking in films like John \& Jane (2005). ${ }^{8}$ It stands in a tradition that may evoke works by Ulrich Seidl, Joshua Oppenheimer, or the playful re-enactments of Abbas Kiarostami as well as mockumentaries like Forgotten Silver (1995). ${ }^{9}$ The latter genre is especially interesting to consider, given that mockumentaries, too, use conventions of documentary filmmaking to blur the line to fiction, although they usually cross it and clearly identify the stories as fictional at some point. According to the "schema of degrees" by Roscoe and Hight, mockumentaries of the highest degree 3 (deconstruction) even "represent the 'hostile' appropriation of documentary codes and conventions, and can be said to bring to 
fruition the 'latent reflexivity' which [...] is inherent to mock-documentaries." "10 Deconstructive mockumentaries are "texts where the documentary form itself is the actual subject." 11

Despite the different basis - fictional for mockumentaries, documentary for Buddha.mov - these quotes seem to capture the film's objective remarkably well. Just like mockumentaries reflect on documentary as a form, and tether their connection to factuality in doing so, Buddha.mov uses documentary means to "encourage viewers to develop a critical awareness of the partial, constructed nature of documentary." ${ }^{\prime 2}$ Meanwhile, instead of being a fictional-narrative-turned-documentary, as is the case for mockumentaries, it reverses the trajectory and seems to be a documentary that increasingly turns into a fiction film, and thus similarly undermines factuality. The extent of the fictional elements is not clear, but the traces and hooks the film places along the way contribute to destabilising the scenes that seem documentary in nature as well, providing an avenue through which to question the whole genre.

In this context, the interfaces of the digital devices, most importantly the iPhone, take on a different meaning. Just as documentary codes and conventions ostensibly convey factuality and the recording of reality, the interfaces seem unfiltered and unmanicured - a direct snapshot into the protagonist's life. But here, too, the viewer gradually finds out irregularities, and at some point, an iMessage chat reveals the constructedness of an earlier WhatsApp chat, the director's persona seemingly feeding lines to Mangaldas (fig. 5 and 6). Here the interface miseen-scène is crucial: the green and white of WhatsApp replaced by the blue and grey of iMessage, signalling a fictional and a "private" chat. Whether or not the latter is indeed an authentic conversation or just another layer is impossible to determine. Which images can be trusted? Which interfaces represent reality? Analogous to using documentary techniques to provoke a reflection of the form, the familiarity of the interfaces is utilised to progressively question their construction and reveal their ambivalences. 

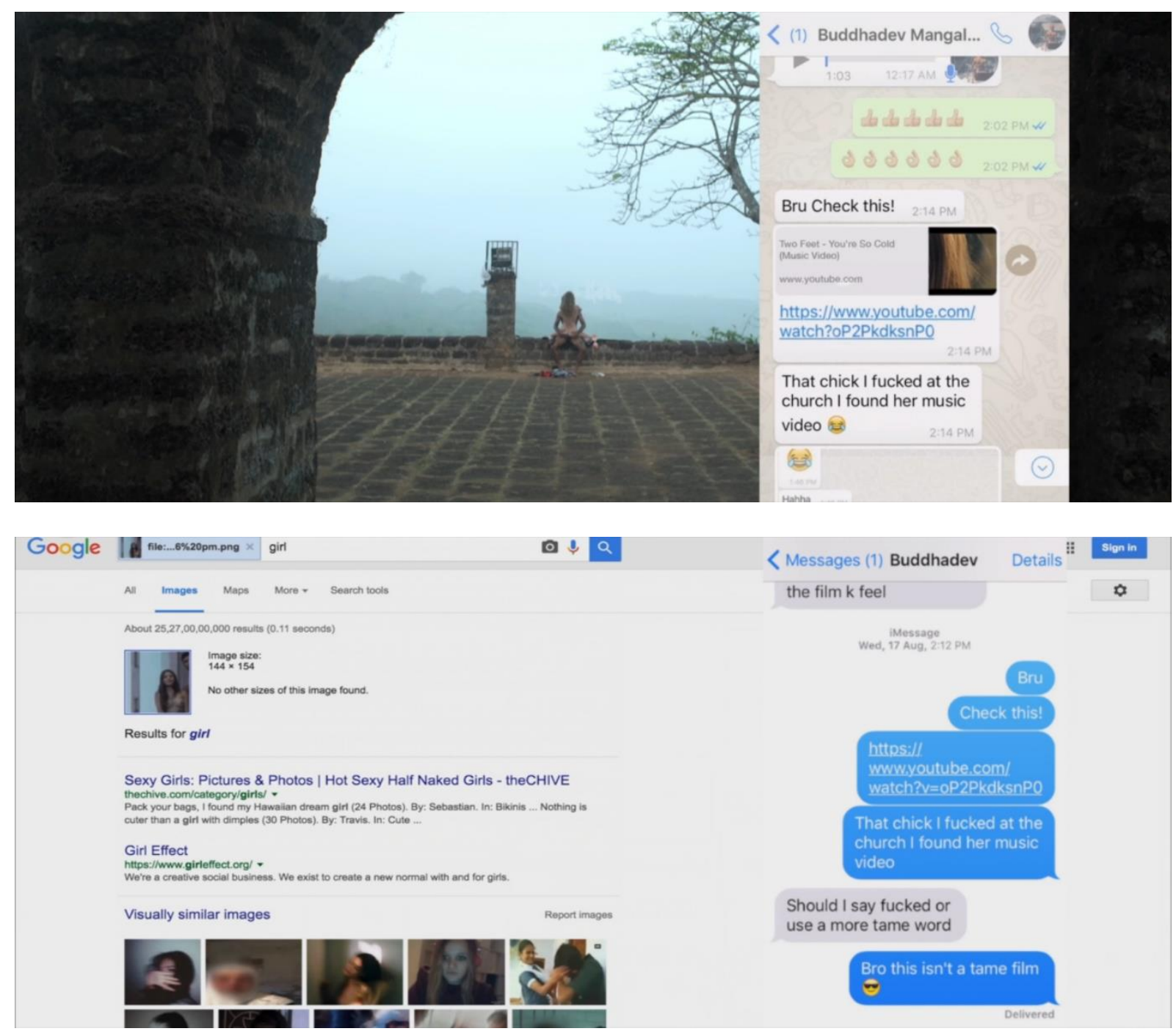

Figure 5 and 6: WhatsApp and iMessage chats at different times of the film

The discourse on fact and fiction the film provokes is then transferred to the technology it showcases and integrates. In a larger sense, it elicits reflections on the apps behind these interfaces, what users feed into them and what is seen from others. It is reminiscent of Sherry Turkle's concept of the digital "second self," a way to externalise parts of our identity to digital devices, as well as to theories of identity performance online, where users may create multiple personalities and "employ impression management (or the selective disclosure of personal details designed to present an idealized self)" just as they would offline. ${ }^{13}$ In parallel to its problematisation of documentary, Buddha.mov thus develops a compelling inquiry into the construction of online selves, the veracity of online visual culture, and the nature of apps like 
Instagram or Tinder as "digital intimate publics." 14 The phone and app interfaces the film integrates reference this, implying privacy while gesturing towards self-marketing and the fictional extent of online identities. The architecture of the film leaves viewers in the position to draw their own conclusions, and consider whether or not Mangaldas's public image is as staged as some of the scenes of the film. ${ }^{15}$

Buddha.mov weaves a complex web of references blurring fact and fiction. As a result, the interface mise-en-scène also turns inwards, exposing the aforementioned reference to regulation that Distelmeyer intends. The design of our phones and apps is not neutral; it is envisioned for certain operations on the surface, while it restricts or hides others, like surveillance and datafication. The interfaces then are just as opaque as the film images' relation to reality, their apparent innocence just as fictional as the idealised selves we construct online. Writing about pixelated phone images from the beginning of the Iraq War in 2003 that were broadcast on CNN as documentary proof, Hito Steyerl points out a crucial twist to their relation to factuality:

The truth of these images proves itself on the level of form: The form of their construction constitutes the real reproduction of their conditions. Their content may or may not correspond to reality - the doubt about it will never be completely removed. Its form, however, will inevitably tell the truth about the context of the image itself, its production, and their conditions. ${ }^{16}$

If we adapt this sentiment, the smartphone interfaces in Buddha.mov develop a different kind of relationship to truth through their form, whether they correspond to factual events or not. In this sense, they are true markers of the screen-sphere, of our daily phone usage, and our digital selves. No matter their actual content, their integration represents the digitalised everyday of Mangaldas, the director, and many viewers, in this way definitively transcending the line between fact and fiction. Buddha.mov thus alerts viewers to the ambivalences of the interfaces 
and apps they use daily, pointing out their "aesthetics of regulation" and questioning their neutrality. ${ }^{17}$

Similar to a mockumentary in its reflection of documentary conventions, Buddha.mov is able to destabilise the foundation of its narrative, its images, and truthfulness through metacommentaries and self-reflexive gestures. By intertwining this discourse on fact and fiction with the phone interfaces, it turns their interface mise-en-scène inwards, undermining them just as the film images' connection to reality. The film becomes a complex case study of contemporary visual culture, with reflections on documentary filmmaking, idealised online selves, relationships in the age of the smartphone, and the nature of interfaces, reminding viewers of the interplays of fact and fiction on their own phones.

\section{Notes}

${ }^{1}$ See Bill Nichols, Introduction to Documentary, 2nd edition (Bloomington, IN: Indiana University Press, 2010 [2001]), 31-32 for the principal modes of documentary filmmaking. Buddha.mov generally uses a mix of the observational, participatory, and reflexive mode.

2 For more on sport documentaries, see Ian McDonald, "Situating the Sport Documentary,"

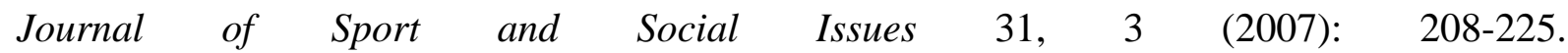
https://doi.org/10.1177/0193723507304608.

${ }^{3}$ Vivian Sobchack, "From Screen-Scape to Screen-Sphere: A Meditation in Medias Res," in Dominique Chateau and José Moure (eds), Screens: From Materiality to Spectatorship (Amsterdam: Amsterdam University Press, 2016), 157-175. For more on ubiquitous computing, see Ulrik Ekman et al. (eds), Ubiquitous Computing, Complexity, and Culture (New York, NY: Routledge, 2016).

${ }^{4}$ Desktop films like Transformers: The Premake (Kevin B. Lee, 2014) or Searching (Aneesh Chaganty, 2018) "incorporate the [computer] desktop environment in the narrative by way of a combination of pre-recorded desktop footage and other sources, including original or found footage, as well as PC-delivered data." Miriam De Rosa and Wanda Strauven, "Screenic (Re)orientations: Desktop, Tabletop, Tablet, Booklet, Touchscreen, Etc.," in Susanne Ø. Sæther and Synne T. Bull (eds), Screen Space Reconfigured (Amsterdam: Amsterdam University Press, 2020), 231-262, here 249.

${ }^{5}$ Jan Distelmeyer, Machtzeichen: Anordnungen des Computers (Berlin: Bertz + Fischer, 2017), 81 (orig. emphasis). See also Jan Distelmeyer, "Drawing Connections - How Interfaces 
Matter," Interface Critique Journal 1 (2018), eds. Florian Hadler, Alice Soiné, Daniel Irrgang. DOI: 10.11588/ic.2018.0.44733.

${ }^{6}$ Distelmeyer, "Drawing Connections," 29 (orig. emphasis).

${ }^{7}$ This is similar to a scene in Kabir Mehta's debut short film, Sadhu in Bombay (2016), which could also be described as a docu-fiction. Here, the film suddenly exits 'full screen mode' to reveal a Mac interface as well, that time a video editing software. The cursor goes on to cut the ending of the sequence just seen, a part in which the protagonist broke character, and instead adds another shot, a close-up, shifting the focus to the process of editing.

${ }^{8}$ See Devansh Sharma, "Buddha.Mov Director Kabir Mehta Talks of Treading the Fine Line of Docu-Fiction, and His Experimental Take on Voyeurism," Firstpost.com, May 232019 , accessed April 18, 2021, https://www.firstpost.com/entertainment/buddha-mov-director-kabirmehta-talks-of-treading-the-fine-line-of-docu-fiction-and-his-experimental-take-on-

voyeurism-6634201.html. The term is also used in the literature, albeit without the hyphen and in a broader sense: Gary D. Rhodes and John P. Springer (eds), Docufictions: Essays on the Intersection of Documentary and Fictional Filmmaking (Jefferson, N.C: McFarland \& Co, 2006).

John and Jane mixes documentary scenes of an Indian call centre for American customers with sci-fi elements, while Ahluwalia's Miss Lovely (2012) began as a documentary project and only later morphed into a fiction film. For his connection to Kabir Mehta, see Lalitha Gopalan, Cinemas Dark and Slow in Digital India (Cham, CH: Palgrave Macmillan, 2020), 57-58.

${ }^{9}$ For more on hybrid forms between documentary and fiction film, see Alexandra Juhasz and Jesse Lerner (eds), $F$ is for Phony: Fake Documentary and Truth's Undoing (London and Minneapolis: University of Minnesota Press, 2006); Florian Mundhenke, Zwischen Dokumentar und Spielfilm: Zur Repräsentation und Rezeption von Hybrid-Formen (Wiesbaden: Springer VS, 2017); Lyell Davies, "Exit With Uncertainty: Documentary Film and Experiencing Not Knowing," Frames Cinema Journal 12 (2017), accessed April 18, 2021, https://framescinemajournal.com/article/exit-with-uncertainty-documentary-film-andexperiencing-not-knowing/.

${ }^{10}$ Jane Roscoe and Craig Hight, Faking It. Mock-documentary and the Subversion of Factuality, (Manchester and New York: Manchester University Press 2001), 160. See also Oliver Fahle, "Mockumentary - Eine Theorie," in Friedrich Balke, Oliver Fahle and Annette Urban (eds), Durchbrochene Ordnungen. Das Dokumentarische der Gegenwart (Bielefeld: transcript, 2020), 83-101.

${ }^{11}$ Roscoe and Hight, Faking It, 160.

${ }^{12}$ Ibid.

${ }^{13}$ Bernie Hogan, "The Presentation of Self in the Age of Social Media: Distinguishing Performances and Exhibitions Online," Bulletin of Science, Technology \& Society 30, 6 (2010), 379. This terminology draws on Erving Goffman's dramaturgy. For a juxtaposition with Turkle, see Laura Robinson, "The Cyberself: The Self-ing Project Goes Online, Symbolic Interaction in The Digital Age," New Media \& Society 9, 1 (2007), 93-110. For the concept of the "second self", see Sherry Turkle, The Second Self: Computers and the Human Spirit, Twentieth Anniversary edition, incl. new introduction, epilogue, and notes (Cambridge, MA: MIT Press, 
(2005 [1984]). See also Sherry Turkle, Life on the Screen: Identity in the Age of the Internet (New York: Simon and Schuster, 1995).

${ }^{14}$ This concept theorises digital intimacies as displayed and problematised by the film as social capital and labour. See Amy Shields Dobson, Brady Robards and Nicholas Carah (eds), Digital Intimate Publics and Social Media (Cham, CH: Palgrave Macmillan, 2018), especially chapter 1: idem: "Digital Intimate Publics and Social Media: Towards Theorising Public Lives on Private Platforms," 3-28.

${ }^{15}$ In the last third of the film, when the narrative turns to Mangaldas's career in real estate after retiring from professional sports, the film adds to this by explicitly referring to the reputational stakes of the film. After apparently watching an early cut, Mangaldas voices his doubts about the damage it might do to his relationships. He openly wonders whether he should sign the release form of the film and what it would do his reputation.

${ }^{16}$ Hito Steyerl, "Die dokumentarische Unschärferelation: Was ist Dokumentarismus?," in Die Farbe der Wahrheit (Wien: Turia + Kant, 2008), 15 (translated by the author; orig. emphasis). Original quote: "Auf der Ebene der Form erweist sich die Wahrheit dieser Bilder: Die Form ihrer Konstruktion stellt das reale Abbild ihrer Bedingungen dar. Ihr Inhalt kann mit der Realität übereinstimmen oder auch nicht - der Zweifel daran wird niemals völlig auszuräumen sein. Seine Form aber wird unweigerlich die Wahrheit sagen, und zwar über den Kontext des Bildes selbst, seine Herstellung und deren Bedingungen. “

${ }^{17}$ Distelmeyer, "Drawing Connections," 29.

\section{Bibliography}

Davies, Lyell. "Exit With Uncertainty: Documentary Film and Experiencing Not Knowing," Frames Cinema Journal 12 (2017). Accessed April 18, 2021, https://framescinemajournal.com/article/exit-with-uncertainty-documentary-film-andexperiencing-not-knowing/.

De Rosa, Miriam and Wanda Strauven. "Screenic (Re)orientations: Desktop, Tabletop, Tablet, Booklet, Touchscreen, Etc.," in Screen Space Reconfigured edited by Susanne Ø. Sæther and Synne T. Bull, 231-262. Amsterdam: Amsterdam University Press, 2020.

Distelmeyer, Jan. "Drawing Connections - How Interfaces Matter," Interface Critique Journal 1 (2018), eds. Florian Hadler, Alice Soiné and Daniel Irrgang: 22-32. DOI: 10.11588/ic.2018.0.44733.

Distelmeyer, Jan. Machtzeichen: Anordnungen des Computers. Berlin: Bertz + Fischer, 2017.

Dobson, Amy Shields, Brady Robards and Nicholas Carah (eds). Digital Intimate Publics and Social Media. Cham, CH: Palgrave Macmillan, 2018.

Ekman, Ulrik, Jay David Bolter, Lily Díaz, Morten Karnøe Søndergaard and Maria Engberg (eds). Ubiquitous Computing, Complexity, and Culture. New York, NY: Routledge, 2016. 
Fahle, Oliver. "Mockumentary - Eine Theorie," in Durchbrochene Ordnungen. Das Dokumentarische der Gegenwart edited by Friedrich Balke, Oliver Fahle and Annette Urban, 83-101. Bielefeld: transcript, 2020.

Gopalan, Lalitha. Cinemas Dark and Slow in Digital India. Cham, CH: Palgrave Macmillan, 2020.

Hogan, Bernie. "The Presentation of Self in the Age of Social Media: Distinguishing Performances and Exhibitions Online." Bulletin of Science, Technology \& Society 30, 6 (2010), 377-386. DOI: 10.1177/0270467610385893.

Juhasz, Alexandra and Jesse Lerner (eds). F is for Phony: Fake Documentary and Truth's Undoing. London and Minneapolis: University of Minnesota Press, 2006.

McDonald, Ian. "Situating the Sport Documentary." Journal of Sport and Social Issues 31, 3 (2007): 208-225. https://doi.org/10.1177/0193723507304608.

Mundhenke Florian. Zwischen Dokumentar und Spielfilm: Zur Repräsentation und Rezeption von Hybrid-Formen. Wiesbaden: Springer VS, 2017.

Nichols, Bill. Introduction to Documentary, 2nd edition. Bloomington, IN: Indiana University Press, 2010 [2001].

Rhodes, Gary D. and John P. Springer (eds). Docufictions: Essays on the Intersection of Documentary and Fictional Filmmaking. Jefferson, N.C: McFarland \& Co, 2006.

Robinson, Laura. "The Cyberself: The Self-ing Project Goes Online, Symbolic Interaction in The Digital Age." New Media \& Society 9, 1 (2007), 93-110. DOI: $10.1177 / 1461444807072216$.

Roscoe, Jane, and Craig Hight. Faking It: Mock-documentary and the Subversion of Factuality. Manchester and New York: University of Manchester Press, 2001.

Sharma, Devansh. "Buddha.Mov Director Kabir Mehta Talks of Treading the Fine Line of Docu-Fiction, and His Experimental Take on Voyeurism." Firstpost.com, May 232019. Accessed April 18, 2021, https://www.firstpost.com/entertainment/buddha-movdirector-kabir-mehta-talks-of-treading-the-fine-line-of-docu-fiction-and-hisexperimental-take-on-voyeurism-6634201.html.

Sobchack, Vivian. "From Screen-Scape to Screen-Sphere: A Meditation in Medias Res." In Screens: From Materiality to Spectatorship edited by Dominique Chateau and José Moure, 157-175. Amsterdam: Amsterdam University Press, 2016.

Steyerl, Hito. "Die dokumentarische Unschärferelation: Was ist Dokumentarismus?" In Die Farbe der Wahrheit, 7-16. Wien: Turia + Kant, 2008.

Turkle, Sherry. Life on the Screen: Identity in the Age of the Internet. New York: Simon and Schuster, 1995. 
Turkle, Sherry. The Second Self: Computers and the Human Spirit, Twentieth Anniversary edition, incl. new introduction, epilogue, and notes. Cambridge (MA): MIT Press, 2005 [1984].

\section{Filmography}

Buddha.mov. Directed by Kabir Mehta. India, 2017.

Forgotten Silver. Directed by Costa Botes and Peter Jackson. New Zealand, 1995.

John and Jane. Directed by Ashim Ahluwalia. India, 2005.

Miss Lovely. Directed by Ashim Ahluwalia. India, 2012.

Sadhu in Bombay. Directed by Kabir Mehta. India, 2016.

Searching. Directed by Aneesh Chaganty. Russia/USA, 2018.

Transformers: The Premake. Directed by Kevin B. Lee. USA, 2014.

\section{Author Biography}

Max Bergmann is a PhD candidate at the International Graduate Centre for the Study of Culture (GCSC) at Justus Liebig University Giessen, Germany. In his doctoral project, he researches non-linear narration, digitality, and internet cultures in contemporary film, analysing the intersection of cinema and digital network structures on multiple levels. He recently published an article on communal life with AI and Her (2013) in Film Criticism (44.1) and a chapter on database cinema in the edited volume Forms at Work: New Formalist Approaches in the Study of Literature, Culture, and Media (WVT 2021). 